\title{
A somatização da subjetividade contemporânea: continuidades e rupturas
}

leda Tucherman

Professora adjunta da UFRJ, doutora em Comunicação pela UFRJ, com pós-doutorado pela Instituition de Recherche en Accoustique et Musique. É autora de "Breve história do corpo e de seus monstros" (Lisboa, Ed. Veja, 1999).

Ericson Saint Clair Doutorando em Comunicação pela UFRJ, mestre em Comunicação pela UFF e bacharel em Comunicação pela Uerj. Como bolsista do CNPq, desenvolve tese sobre a construção midiática da depressão, orientada por leda Tucherman.

\section{Resumo}

Investigamos o estatuto do corpo na cultura ocidental contemporânea em uma breve genealogia. Partimos do fenômeno atual da somatização da subjetividade para buscar continuidades e rupturas do modelo disciplinar vigente no século XIX. Sugerimos que as novas modalidades de exercício de poder das sociedades de controle atuam em conjunto com um surpreendente recrudescimento da disciplina na atualidade.

Palavras-chave : corpo; subjetividade; poder

\begin{abstract}
We investigate body's status in contemporary west culture on a brief genealogy. We start from present somatization of subjectivity to find sequences and ruptures of nineteenth century disciplinary model. We suggest new modalities of power in control societies work together with a surprising rise of discipline nowadays.
\end{abstract}

Keywords : body; subjectivity; power 


\section{Introdução}

O corpo não foi desde sempre reconhecido como um objeto teórico. Seu existir ou estar lá passou por outras grades de leitura antes que o dispositivo que gerou a medicina clínica e, complementarmente, a sociedade disciplinar, lhe tenha dispensado o papel que cumpriu no projeto moderno. Acreditamos que este movimento não se fez sozinho e tem relaçôes muito viscerais com transformações bastante profundas que produziram tal contexto.

Neste artigo, buscamos lançar luzes sobre o fenônemo atual da chamada somatização da subjetividade, procurando investigar, em uma breve perspectiva genealógica, quais modelos de exercício de poder sobre o corpo estamos deixando para trás e quais persistem sob novas configuraçóes. Compreender o estatuto do corpo na cultura contemporânea é crucial para as pesquisas da área de Comunicação Social, para as quais frequentemente o corpo é tomado como dado natural, desprovido de uma historicidade própria.

Em um primeiro momento, recordaremos a constituição do corpo disciplinar sugerida por Michel Foucault em seus textos da década de 70, acrescentando referências afins a sua abordagem, de modo a enriquecer nossa pequena genealogia. Em seguida, tratamos de algumas das transformaçóes por que passa a subjetividade contemporânea, comentando a ideia de somatização da subjetividade para, assim, salientar as continuidades e as rupturas do modelo disciplinar.

Este texto nasce de uma observação geral de que muito se tem atentado às possíveis rupturas que as sociedades de controle, brilhantemente descritas por Deleuze, estariam introduzindo na cultura. Este privilégio pelas rupturas, entretanto, pode impedir que se percebam os novos e potentes contornos da velha disciplina na atualidade. Nosso olhar mais atento às formas revigoradas da disciplina nas sociedades de controle é inspirado certamente nas genealogias nietzscheanas e foucaultianas, mas também na perspectiva de Gabriel Tarde, para quem a história não é "um caminho mais ou menos reto, mas uma rede de caminhos muito tortuosos e todos semeados de encruzilhadas" (TARDE, 1999, 155).

\section{A produção do corpo disciplinar}

Sem dúvida, o conceito de vida e de vivo foi um produto da virada do século XIX. Tal conceito foi entendido como correspondente a uma unidadecorpo dotada de uma historicidade orgânica, de uma finitude que lhe era radicalmente própria, de uma singularidade absoluta, que remetia à fatalidade ontológica de um ter que ser (e, sendo de tal maneira, ser definitivamente assim) e de uma sexualidade reprodutiva que era ladeada por um desejo livre. Correspondeu, ao mesmo tempo, a um conjunto de fatores complementares: o primeiro e decisivo concerne à organização da biopolítica de que nos fala Foucault, tanto na anátomo-política dos corpos iniciada nos séculos XVIIXVIII, quanto na vertente da biopolítica da população, encarregada dos nascimentos, longevidade, reprodução etc. 
De modo geral, as disciplinas são técnicas que impóem uma ordenação às multiplicidades humanas. Respondem a uma conjuntura histórica conhecida: a explosão populacional do século XVIII e o crescimento e a complexificação do aparelho de produção. Do final do século XVII às vésperas da Revolução Francesa, multiplica-se a população de alunos assim como a população dos hospitais. Nos exércitos franceses, por exemplo, tem-se cerca de 200.000 homens ao final do século XVIII (FOUCAULT, 1977). Assim, as disciplinas devem correlacionar os dois fatores, garantindo as diversas formas de produção: de saber nas escolas, de saúde nos hospitais, de força destruidora nos exércitos. Fazem isso respondendo a três critérios: tornam o exercício do poder menos custoso econômica e politicamente, fazem os efeitos do poder ser estendidos o máximo possível sem lacunas e fazem aumentar a docilidade e a utilidade dos aparelhos pedagógicos, militares, industriais, médicos etc.

Dito de outro modo, nas disciplinas formam-se corpos dóceis, sendo que "é dócil um corpo que pode ser submetido, que pode ser utilizado, que pode ser transformado e aperfeiçoado" (FOUCAULT, 1977, 126). Apesar de o uso do corpo ser algo mais ou menos constante na história, vemos algumas especificidades deste período. Em primeiro lugar, em relação à escala do controle: não mais a massa indivisível de corpos, mas o corpo singular, o poder infinitesimal sobre o corpo. Em seguida, o objeto do controle: não mais apenas os elementos significativos dos comportamentos ou a linguagem do corpo, mas a economia dele, a eficácia dos movimentos, a organização interna. A coação se dá mais sobre sua força. Finalmente, a modalidade de ação sendo ininterrupta, atençáo contínua sobre os processos do corpo. Assim, "esses métodos que permitem o controle minucioso das operaçóes do corpo, que realizam a sujeição constante de suas forças e lhes impóem uma relação de docilidade-utilidade, são o que podemos chamar de disciplinas" (Ibid., 126).

\section{Modernização da percepção: atenção e sugestão social}

Os novos tempos - pautados por exaustiva aceleração da vida urbana - exigiam a produção de corpos esquadrinháveis, domesticáveis, gerenciáveis e tornados aptos ao trabalho moderno em suas esferas mais distintas. Em suas recentes teses, expostas nos livros Techniques of the observer e Suspensions of perception: attention, spectacle and modern culture, o historiador de Artes Jonathan Crary propóe que, em torno da segunda metade do século XIX, ocorrera um profundo e significativo deslocamento epistemológico no que tange à percepção humana. Tal descontinuidade de práticas e discursos referentes à percepção seria simultânea à ascensão de novas modulaçóes do sistema capitalista. No que tange aos regimes de observação, o deslocamento se daria de um modelo de percepçáo baseado na estabilidade e centralidade do sujeito para um regime em que a materialidade do corpo humano - com suas instabilidades, fluxos e temporalidades próprios - seria condição para toda experiência perceptiva. Em um trabalho de inspiração tanto arqueológica quanto genealógica, o historiador torna evidente o próprio caráter histórico da percepção humana. 
Jonathan Crary indica que esta mudança de paradigma terá como conseqüência, no final do século, a ascensão do tema da atenção. O surgimento de um novo modelo epistemológico que constitui seus regimes de verdade a partir da corporeidade do sujeito, em que a prioridade da consciência na garantia de representação absoluta do mundo é problematizada, suscita o interesse na investigação do problema da atenção. Em outras palavras, quando o sujeito deixa de ser sinônimo de uma consciência que é essencialmente autopresente, quando não há mais a inevitável congruência entre subjetividade e pensamento, a atenção passa a ser importante, pois ela será o novo princípio regulador de garantia da consistência do mundo para o sujeito. Assim, destacar-se-iam duas condiçóes para a ascensão da atenção como interesse epistemológico: a primeira delas relacionada ao colapso dos modelos clássicos de visão e do sujeito estável, pontual, que esses modelos pressupunham. A segunda refere-se à insustentabilidade de soluçóes apriorísticas para problemas de caráter epistemológico.

O levantamento histórico de Jonathan Crary indica-nos que a "atenção", no século XIX, encerra grande volatilidade, referindo-se tanto à atenção como a conhecemos (ou seja, estado provocado pelo desprendimento de um campo de atração mais amplo para concentração ou foco em um reduzido número de estímulos) quanto a outros estados, como o transe, o devaneio e a hipnose. Ou seja, ela é compreendida em termos de fluxos e intensidades, e não em termos de fixação e estabilidade. Sendo assim, a atenção como a concebemos comumente seria apenas mais um estado deste amplo continuum que envolveria outras nuances de percepção, regimes mentais e subjetivos.

É como se a atenção contivesse em si própria as condiçôes de sua desintegração, como se fosse "assombrada pela possibilidade de seu próprio excesso" (CRARY, 2000, 47) como nossa experiência poderia atestar quando fixamos nossos sentidos por muito tempo em um só foco. De diversas formas, a atenção poderia atingir um limite em que ocorreria, por um lado, a própria deterioração da identidade do objeto percebido e, por outro, uma mutação em seu próprio estado, como nos casos do transe ou da hipnose. Logo,

a atenção então se torna um meio impreciso de designar a capacidade relativa de um sujeito para isolar seletivamente certos conteúdos de um campo sensorial à custa de outros, no interesse de manutenção de um mundo produtivo e ordenado (Ibid., 12).

Considerando-se que a atenção, a partir da segunda metade do século XIX, deve ser compreendida como um continuum em que estão incluídos outros estados perceptivos, como o devaneio, o transe ou a hipnose, permitimonos afirmar que atenção e distração não são estados essencialmente estanques. Eles funcionam em um processo brusco, dinâmico e contínuo, de fluxos e intensidades, de acordo com as exigências do consumo capitalista. Sendo assim, o problema da atenção, então,

[...] não era uma questão de atividade neutra e eterna como respirar ou dormir, mas de emergência de um modelo especifico de comportamento com uma estrutura histórica especifica - comportamento que era articulado em termos de normas determinadas socialmente e que era parte da formação de um meio tecnológico moderno [...] 


\begin{abstract}
Este problema foi elaborado em um sistema econômico emergente que demandava atenção de um sujeito em uma ampla gama de novas tarefas produtivas e espetaculares, mas cujo movimento interno foi continuamente erodindo a base de qualquer atenção disciplinar. Parte da lógica cultural do capitalismo demanda que aceitemos como natural adaptarmos nossa atenção rapidamente de uma coisa a outra. O capital, como troca e circulação aceleradas, necessariamente produziu este tipo de adaptabilidade perceptiva e tornou-se um regime de distração e atenção recíprocas (Ibid., p. 29).
\end{abstract}

O sonho moderno de autonomia do sujeito é posto em questão, uma vez que a própria consciência é problematizada. Em seu lugar, perscruta-se a atenção - essencialmente fluida e fugidia - como independente da própria consciência. É neste contexto que surgem afirmaçóes como esta de Gabriel Tarde, a respeito do homem social:
o estado social, como o estado hipnótico, não é senão que uma forma de sonho, um sonho de comando e um sonho de ação. Não ter as idéias sugeridas e conceber suas crenças como espontâneas: tal é a ilusão própria do sonâmbulo, assim como a do homem social (TARDE, 2000, 137).

Ao relativizar as fronteiras entre consciente e inconsciente, qualificando o estado social como estado de sonho, Tarde salienta as ilusóes modernas de autonomia de todos nós, autênticos "sonâmbulos". O que o filósofo denomina sugestão social não difere em natureza do estado sonambúlico descrito pelos estudiosos da atenção e da hipnose. A sugestão social seria apenas menos direta que a sugestão hipnótica, porém seus efeitos perdurariam mais. Ao estalar dos dedos do hipnotizador, o mundo do paciente se restaura. Ora, não há estalar de dedos quando se está permanentemente embriagado pela sugestão social. $\mathrm{O}$ sonambulismo social seria menos intenso, porém poderia alastrar-se por um território muito mais amplo: cidades, países, continentes se rendem a esta curiosa forma de entrega. Finalmente, a sugestão social seria certamente menos rápida que a hipnótica. Contudo, a profundidade de sua atuação seria infinitamente maior (TARDE, 1999, 144). Os efeitos de uma sugestão social perduram até que sejam substituídos por novas formas de sugestão social.

Sabemos hoje que os estudos de Tarde foram suplantados pelo método sociológico de Émile Durkheim. Olhando o mesmo contexto de outro ponto de vista, acompanhados pelo estudo de Lepenies (1996), As três culturas, este teria sido o momento em que a literatura começava a perder a disputa pela primazia de oferecer sentido e orientação à vida dos homens modernos. Surgia para exercer tal função um campo de ciências ditas então morais, às quais chamamos de ciências humanas. No entanto, e desde o seu nascedouro, estas disciplinas buscaram afirmar sua cienticidade recorrendo ao modelo lógico das ciências naturais, o que nos parece ter facilitado, no universo simbólico da medicina, por exemplo, o escorregar da palidez das moças sonhadoras para a palidez tuberculosa das bactérias.

Esta perscrutação íntima do corpo disciplinar é parte de um contexto em que uma utopia específica se fortifica: a utopia da transparência absoluta. 


\title{
A utopia da transparência absoluta
}

Em nossa pequena genealogia, outro fator, assim como os anteriores, é dotado de uma historicidade própria e acidentada: foi o surgimento de um conjunto de técnicas de exame que realizaram clinicamente parte da promessa iluminista de transparência. Este percurso foi e ainda é ligado a um antigo desejo de transparência absoluta, traço nascente da utopia moderna, muito bem explorado no livro de Jean Starobinski, Jean-Jacques Rousseau: a transparência e o obstáculo, responsável, certamente, pelo extraordinário investimento nas possibilidades de visibilidade e visualização que o marcaram ${ }^{1}$.

Através do exame, é possível vigiar, qualificar, hierarquizar e punir. Dissemina-se por todo o corpo social, como no hospital, na escola, no exército. O exame inverte a economia da visibilidade no exercício do poder, pois a visibilidade não é privilégio daqueles que detêm o poder como antes da disciplina, mas daqueles sobre os quais o poder é exercido. Faz também a individualidade entrar em um campo documentário, com relatórios constantes, transcrições e descriçôes do corpo que permitem o acúmulo de documentos para posterior comparação, qualificação e hierarquização. $\mathrm{O}$ exame faz de cada indivíduo um "caso". Antes da disciplina, as histórias pessoais, as sagas, eram privilégio dos homens ilustres. Com ela, o que se descreve é a vida dos infames, como nos mostra Foucault:

\begin{abstract}
Durante muito tempo a individualidade qualquer - a de baixo e de todo mundo - permaneceu abaixo do limite de descrição. Ser olhado, observado, contado detalhadamente, seguido dia por dia por uma escrita ininterrupta era um privilégio. A crônica de um homem, o relato de sua vida, sua historiografia redigida no desenrolar de sua existência faziam parte dos rituais do poderio. Os procedimentos disciplinares reviram essa relação, abaixando o limite da individualidade descritivel e fazem dessa descrição um meio de controle e um método de dominação. Não mais um monumento para uma memória futura, mas documento para uma utilização eventual. E essa nova descritibilidade é ainda mais marcada, porquanto é estrito o enquadramento disciplinar: a criança, o doente, o louco, o condenado se tornarão, cada vez mais facilmente a partir do século XVIII e segundo uma via que é a dos mecanismos de disciplina, objeto de descriçóes individuais e de relatos biográficos. Esta transcriçãa por escrito das existências reais não é mais um processo de heroificação; funciona como processo de objetivação e de sujeição. A vida cuidadosamente estudada dos doentes mentais ou dos delinquentes se origina, como a crônica dos reis ou a epopéia dos grandes bandidos populares, de uma certa função política da escrita, mas numa técnica de poder totalmente diversa (FOUCAULT, 1977, 170).
\end{abstract}

Como insinuado acima, transparência significa também possibilidade de controle e de cálculo. Vale lembrar que, dos nossos cinco sentidos, a visão é a que estabelece a separação e a distância ideal entre o sujeito e o objeto: ver bem é estar no correto ponto-de-vista, o que, no Ocidente, gerou uma fenomenologia onde "ver é conhecer". Lembremos da longa viagem de Ulisses na Odisséia de Homero: ele pode ver todas as coisas, seja do mundo dos vivos ou do reino de Hades, o mundo dos mortos. Entretanto, tem que se amarrar ao mastro do navio para se proteger do encantamento gerado pelo canto das sereias. 
Não deve nos espantar, portanto, quando Virilio nos classifica como uma civilização que tem hipertrofia da visão, especialmente porque ele nos lembra a relação explícita entre o surgimento de instrumentos que aperfeiçoam a visão e as guerras: as câmaras fotográficas e de cinema ou vídeo se especializando para dar conta do movimento dos exércitos inimigos e/ou para divulgar as imagens de guerra na espetacularização dos meios de comunicação de massa no cinema e na televisão, sobretudo.

Há, ainda, uma coincidência além das guerras mundiais que o século $\mathrm{XX}$ viveu e que alteraram as idéias de vida e morte, tanto numérica quanto qualitativamente, uma vez que o holocausto e a bomba atômica evidenciaram a crueldade radical da associação entre tecnologia e guerra: foi o momento inaugural em que a política apareceu como planejamento e como técnica, o que envolveu premissas e imperativos diferentes. Fez parte da política moderna a idéia de limites, seja entre eu e o outro, este ou aquele país, a própria natureza e a cultura. A noção de contrato social com sua relaçáo de direitos e deveres explicita esta realidade.

Afinal, a conjuntura política, que também fez sua aparição no mesmo século, decretou que todos os homens tinham direito à saúde, agora um novo direito humano, que deveria ser garantido pelo Estado do bem-estar social, ou Estado Providência, tal como o nomeiam alguns teóricos.

A técnica atual, medida pela lógica da eficiência, repousa sobre o princípio inverso de ausência de limites. Faz parte da sua natureza o esforço de não reconhecê-los, em primeira instância, ou em superá-los, no segundo momento. E não se pode pedir ao escorpião que não morda ou desejar que a águia não busque a rapina. É da sua natureza, como nos lembram a fábula e também Nietzsche.

Curiosamente, então, este direito à saúde foi encampado por uma lógica técnica. Esta é hoje o lugar em que se joga a relação entre o real e o possível, mas as condiçôes do jogo foram alteradas: parecemos ter erradicado o impossível, que aparece em novas condiçóes temporais, ou seja, como ainda não possível, ou, principalmente, como economicamente inviável.

\section{A somatização da subjetividade e o recrudescimento da disciplina}

É neste o cenário que teóricos contemporâneos têm atentado para a formação da cultura somática (especialmente o sociólogo Nikolas Rose e, no Brasil, o filósofo Francisco Ortega), em que prevalecem as biossociabilidades (RABINOW, 2002). Em outras palavras, assistimos à biologização de todas as esferas da vida e da subjetividade, tendo os media um papel decisivo neste contexto. Essa tendência à biologização da subjetividade é reforçada, ainda, no campo das neurociências e da genética, em que profundas alteraçôes dos jogos de saber e poder estão sendo promovidas. Nesse contexto, o Projeto Genoma talvez seja a mais ambiciosa proposta de reformulação de saberes e poderes sobre o homem. Como é amplamente sabido, os cientistas dedicados a esse empreendimento buscam realizar o total mapeamento de genes que constituem o humano. Segundo Paul Rabinow, o Projeto Genoma é técnico-científico em dois sentidos específicos: tanto na medida em que crê que o desenvolvimento 
técnico permitirá alcançar os resultados pretendidos quanto na medida em que tal conhecimento permitirá intervir nos genes e produzir novos tipos de humanos. A aposta de Rabinow "é que a nova genética deverá modelar a sociedade e a vida com uma força infinitamente maior do que a revolução física jamais teve, porque será implantada em todo o tecido social por práticas médicas e uma série de outros discursos" (RABINOW, 2002, 143). Assim, por exemplo, os cientistas crêem poder identificar, no futuro, a partir do mapa genético de uma pessoa, todas as propensóes que ela teria para desenvolver determinadas doenças. Desta forma, a prevençáo contemporânea corresponderia basicamente a um mapeamento de riscos.

O que a técnica aprimora imediatamente é a ordem do cálculo, e, assim, o tal direito à saúde afirmou-se como direito à não doença, o que correspondeu à afirmação dos perigos do contágio e ao combate aos riscos. É porque, na verdade, qualquer pessoa saudável é apenas alguém que ignora suas doenças, atuais ou virtuais:

\begin{abstract}
Doravante não é fácil falar de normalidade, no máximo de média e de intervalo confiável, e os números levam à definição do risco mais do que de uma patologia. Trazemos dentro de nós mesmos um pecado original, um risco multiforme que teve origem em nossos genes, modificado pelo nosso meio ambiente natural e sociocultural pelo nosso modo de vida. Na sala de espera do médico, agora, há cinco bilhóes de clientes aguardando pacientemente (MOULIN, 2008, 19).
\end{abstract}

Como vimos nos tópicos anteriores, claro está que não foi aí que nos deparamos pela primeira vez na história do Ocidente com a noção de contágio e o medo que dela advém. Quando olhamos para o século XVI, pensamos imediatamente nas Grandes Navegaçóes, presença contemporânea lógica da nova concepçáo de mundo em que o centro foi destituído de sua categoria ontológica na passagem do mundo fechado ao universo infinito, conforme o fascinante título do livro de Koyré, de 1973.

Este século funda a ex-centricidade humana, que corresponde a um duplo movimento: perder a destinação e ganhar a liberdade de "tudo poder e nada ser" como no enunciado célebre de Giordano Bruno. Este mesmo tempo é descrito como o de um momento onde as misturas, as perdas de identidade, o esmaecimento dos limites foram acolhidos, desejados e mesmo produzidos, o que podemos associar exatamente a esta nova e radical disposição para a liberdade. Também será ela que, desligando o homem dos desígnios divinos, o exporá a perigos que até então eram desconhecidos e/ou desvalorizados: "Quando reinos, gêneros, espécies, sexos, costumes e civilizaçóes se misturam, surgem ameaças de toda ordem, ameaças a toda ordem: surgem a poluiçáo e o contágio" (FIGUEIREDO, 1990, 36).

O recurso a este recuo não foi gratuito: vemos afinidades nestas duas experiências de globalização. Elas descrevem a fragilização das fronteiras interiores, falam de homens que se misturam, que se confundem e podem agora contaminar. A sensibilidade quinhentista usou como processo de defesa, quase de blindagem, o recurso memorialista, gerando um uso específico para a memória, a 
saber, o de estabilizar, conferindo permanência e continuidade a estas experiências individuais e coletivas sujeitas a conversôes e mutaçóes: "Falar de si, falar de suas conversóes e de suas doenças, seria então, uma estratégia para reconquistar imaginariamente a unidade da vida e a integridade do corpo" (Ibid., 45).

Desde então e até hoje, as noçôes de perigo, contágio e mistura não mais nos abandonaram. No entanto, mudaram de canal de expressão, ou seja, desta origem literária onde nasceram, que devia dar sentido à vida e à morte, migrando para o que Lepenies chamou de "ciências morais" (LEPENIES, 1996) e, muito rapidamente depois, para as ciências naturais, as do exame e do cálculo. Foi assim que substituímos as memórias pelos exames através de num investimento científico e tecnológico que, nascendo em um campo externo à própria biologia, ou à clínica médica, o das técnicas de visibilidade, realizou o extraordinário desenvolvimento das técnicas de visualização do corpo.

Tal desenvolvimento tem seu início na descoberta dos raios-X (1895) e prossegue passando por endoscopias, ultrassonografias, ressonâncias magnéticas e PET-scans, permitindo que absolutamente tudo seja visível e, portanto, conhecido no que toca ao humano. Doravante não serão os pacientes ou os cidadãos e seus sintomas que chorarão seus males e falarão de suas dores: será esta doença suspeita em todo quadro de saúde que merecerá a absoluta atenção dos indivíduos e das instituiçôes. Dizendo de outra maneira, é neste processo que a biologia desliga-se da terapia e passa a atuar na regulação da vida, promulgando uma economia do bem-estar que é também uma radical medicalização da sociedade.

Vale lembrar Deleuze, em seu profético Post-scriptum sobre as sociedades de controle, texto em que alertou que os indivíduos formados pela disciplina tornavam-se pouco a pouco dividuais, ou seja, cada vez mais amostras e bancos de dados, seres cindidos em perene competição consigo próprios e equacionados em termos de informaçóes codificáveis. Neste sentido, alertava sobre a "nova medicina 'sem médico nem doente', que resgata doentes potenciais e sujeitos a risco, que de modo algum demonstra um progresso em direção à individuação, como se diz, mas substitui o corpo individual ou numérico pela cifra de uma matéria 'dividual' a ser controlada" (DELEUZE, 1992, p. 225).

O controle da tal matéria "dividual" no campo da medicina contemporânea se dá basicamente a partir da gestâo de riscos. Alimentada pelas novas verdades provenientes da genética e das neurociências, a gestão de riscos na medicina vai ao encontro dos prognósticos deleuzianos. A prevenção de doenças segundo a lógica da genética e do saber neurocientífico trabalha no sentido de uma gestáo de fatores de uma série de riscos em bancos de dados. Segundo Rabinow,

\footnotetext{
o risco não é o resultado de perigos especificos colocados pela presença imediata de uma pessoa ou um grupo de pessoas, mas sim a fusão de "fatores" impessoais que tornam um risco provável. Assim, a prevenção éa vigilância, não do indivíduo, mas sim de prováveis ocorrências de doenças, anomalias, comportamentos desviantes a serem minimizados, $e$ de comportamentos saudáveis a serem maximizados. Estamos aos poucos abandonando a antiga vigilância face-a-face do individuo e grupos já conhecidos como perigosos ou doentes, com finalidades disciplinares ou terapêuticas, e passando a projetar fatores de
} 
risco que desconstroem e reconstroem o sujeito individual ou grupal, ao antecipar possiveis loci de irrupçôes de perigos, através da identificação de lugares estatisticamente localizáveis em relação a normas e médias. (RABINOW, 2002, 145).

Diante desse novo arranjo de forças, a própria idéia de doença é relativizada em benefício da noção de deficiência. Estaríamos, segundo Rabinow, diante de uma "morte da clínica", visto que esta teria se formado, como mostrou Foucault, no mesmo contexto da emergência do indivíduo. A deficiência seria, portanto,
qualquer condição física, mental ou situacional que produziria fraqueza ou problema em relação ao que é considerado normal (...) Seriam déficits a serem compensados psicológica, social e espacialmente e não doenças a serem tratadas: ortopedia, não terapêutica (Ibid., p. 146).

Vale lembrar que parte do imenso prestígio de que desfrutam as biotecnologias advém da sua capacidade de dar a ver a que já nos referimos. Vimos, entretanto, unindo-se a esta capacidade, desde os anos 60, a poderosa indústria dos fármacos, princípios de atuação direta, lá onde a vida faz sintoma, e, a partir do fim do século passado, a pesquisa do genoma com todas as promessas de erradicaçáo das mortes naturais, desde que estejamos gerenciando as informaçóes que recebemos nas práticas cotidianas que demandam total atenção aos nossos corpos e mentes.

Assim, tanto a saúde tornou-se um valor em si mesmo, um padrão para julgar e rejeitar comportamentos e condutas, a partir da avaliação dos riscos aí implicados, quanto se procedeu a uma "somatização da subjetividade"2. Inventase, então, uma inversão do olhar e da percepção: não é o corpo a base do cuidado de si, mas, ao contrário, o eu hoje existe para cuidar do corpo ${ }^{3}$.

Ocorre que, curiosamente, apesar da emergência desta matéria dividual que póe em cheque o modelo do indivíduo da disciplina, podemos perceber novas configuraçóes da disciplina no contemporâneo, certamente servindo agora a outros objetivos que não eram os mesmos daqueles já longínquos séculos XVIII e XIX. O fato é que este recrudescimento da disciplina é, às vezes, pouco destacado nesta sociedade dita de controle. Como têm notado os teóricos do capitalismo cognitivo, como Negri, Lazzarato e outros, há uma exacerbada atenção à própria atenção e à memória na atualidade. Não podemos nos esquecer, contudo, que esta atenção não se dá apenas no controle em ambientes abertos, mas simultaneamente por meio de uma pesada ortopedia da própria atenção individual. Os corpos que permanecem horas em frente aos computadores são capazes de manter regimes atentivos distintos e modulados somente em um contexto histórico-social como o nosso, em que os saberes e poderes se organizam de modo a perscrutar os mínimos recônditos da percepção humana, em uma clara atualização da anátomo-política do corpo humano de que nos falava Foucault em seus estudos sobre a disciplina e o biopoder.

Isto aparece, ainda, na rigidez dos exercícios e da obediência a um conjunto imenso de normas que incluem alimentação controlada, codificação da relação com as bebidas alcoólicas e energéticas, check-ups permanentes, num apertado controle de si e de um virtual uso dos prazeres. Não foram poucos os teóricos que viram na prática do body-building sua genealogia religiosa. Mas aparece também na patologização dos que parecem estar "fora do ritmo", em geral vistos como 
deprimidos (tome Prozac) ou vítimas de TDA, distúrbios de atenção e hiperatividade, comuns nos diagnósticos das crianças que passam a ser "normatizadas" à base de ritalina.

Assim, a matéria dividual do controle de riscos e de fatores impessoais convive claramente em nossa contemporaneidade com uma disciplina repaginada, em que as técnicas de exame são aperfeiçoadas, a atenção ao próprio corpo é superestimulada e os mecanismos de vigilância são plenamente interiorizados.

\section{Considerações finais}

Procuramos contribuir para o debate das relaçóes entre cultura, corpo e subjetividade buscando lançar luzes sobre a insidiosa, porém penetrante, reconfiguração das técnicas disciplinares na sociedade contemporânea. Percebemos sintomas de que talvez o modelo do controle elaborado por Deleuze esteja de fato, quase vinte anos após o profético texto, amparado por uma nova disciplina, com novas colorações.

Em nossa fascinante e paradoxal cultura somática, vemos, ao mesmo tempo, os saberes e poderes pulverizando o indivíduo tradicional, como na medicina de fatores de risco e nos trabalhadores cognitivos, e, por outro lado, produzindo novos corpos dóceis, como aqueles trabalhados nas academias de ginástica e tornados hipnotizados pelas telas de computadores.

No que diz respeito ao corpo e à subjetividade, portanto, a história parece-nos mais surpreendente a cada nova mirada. Na história do corpo, não há tirania das rupturas, assim como não existe ditadura das continuidades. Há jogos plurais, multicoloridos, nuances e acasos que eclodem em puro movimento. Domesticar essa história com esquemas teóricos rígidos é, ao nosso ver, ignorar as contradições e riquezas do tempo humano. 


\section{Notas}

${ }^{1} \mathrm{O}$ célebre panóptico, inventado pelfilósofo utilitarista inglês Jeremy Bentham em 1785, e considerado como a primeira tecnologia de poder por Foucault, surge respondendo a este imperativo de transparência, contra a escuridáo opaca das masmorras reais.

2 Expressão feliz cunhada por Francisco Ortega em seu livro "O Corpo Incerto", de 2007.

3 Um cuidado de si sempre tenso, pois também sofre uma espécie de terrorismo informacional na medida em que primeiro devemos evitar consumir certos elementos, depois devemos buscá-los, o que nos deixa sem nenhuma garantia de estabilidade de referências: já vimos isto com sal, ovo, açúcar, café, primeiro considerados venenos, agora necessários, como também já vimos o oposto: vinho tinto em doses moderadas era excelente como vaso dilatador e anti-oxidante e agora parece ser geralmente nocivo.

\section{Referências bibliográficas}

CRARY, Jonathan. Suspensions of perception: attention, spectacle and modern culture. Cambridge/Massachusetts: MIT Press, 2000

DELEUZE, G. "Post-scriptum sobre as sociedades de controle". In: Conversaçôes. Rio de Janeiro: Ed. 34, 2002.

FIGUEIREDO, Luiz Cláudio. A invenção do psicológico: quatro séculos de subjetivação 1500-1900. São Paulo: EDUC, 1990

FOUCAULT, Michel. Vigiar e punir: nascimento da prisão. Petrópolis: Vozes, 1977

LEPENIES, Wolf. As três culturas. São Paulo: Edusp, 1996

MOULIN, Anne Marie. "O corpo diante da medicina”. In: História do Corpo 3: As mutaçóes do olhar. O século XX. (org) Jean-Jacques Courtine. Pertópolis: Vozes, 2008

ORTEGA, Francisco. O corpo incerto. Rio de Janeiro: Garammond, 2008

RABINOW, Paul. "Artificialidade e iluminismo: da sociobiologia à biosociabilidade", in Antropologia da razão. Rio de Janeiro: Relume Dumará, 2002

TARDE, Gabriel. La logique sociale. Paris: Institut Synthélabo, 1999 Les lois de l'imitation. Paris: Éditions du Seuil, 2001 